Journal of Social Sciences 7 (4): 627-631, 2011

ISSN 1549-3652

(C) 2011 Science Publications

\title{
Developing Community Health Conditions for Happiness, Phase 1
}

\author{
Chalard Chantarasombat \\ Department of Research and Academic Network Development, \\ Faculty of Education, Mahasarakham University, Muang District, \\ Maha Sarakham, Thailand 44000
}

\begin{abstract}
Problem statement: Complete health of physical, social and intellectual development is an appropriate plan of human development and raises the quality of life in communities. If the development plan is integrated into the local community it will create peace and generosity. Good health is also fundamental to sustainable development which will create a peaceful society where community members are happy and content. Approach: The purpose of this research in Phase 1, is to (1) Identify leaders in communities at village and sub-district level to drive the ongoing research study and development to achieve good community health conditions in all aspects and dimensions. (2) To have the participants and researchers identify the key elements and indicators of health issues that communities feel are most important to their way of life. Results: Village communities were selected by cluster sampling from the provinces of Roi-Et and Maha Sarakham. The developed model for developing community health for living happily in communities is an appropriate and practical method that can be utilized in other communities. Conclusion: The model is in accordance with Participatory Action Research (PAR) and the procedures are flexible and the development plans which are the results of Phase 1 can be extended to other communities and backgrounds.
\end{abstract}

Key words: Health conditions, community development, Participatory Action Research (PAR), roi-et, maha sarakham, community members, sub-district level, village communities,

\section{INTRODUCTION}

The assembly of government officials and local leaders of sub-districts in projects to resolve health issues in communities rarely succeeds because there is no mechanism for managing the knowledge and integration of the problems by people within the communityand cooperation and an effective network of government organizations ranging from Sub-District

Administrative Organization, Communities and Government Organizations are essential to development of the country's healthcare (Jampawai et al., 2011). The knowledge is needed so that community members can lead themselves; know how to utilize basic resources and live in a peaceful society where there is love, harmony, charity and happiness (Wasi, 2007). It is especially important in managing the 4 basic resources of sustainability and healthy living in material aspects. The problem of Health in communities in the province of Roi-et is one such area that is current facing these problems in Health. There is still minimal cooperation among local leaders in subdistrict, villages, local government agencies, private agencies in creating awareness and a proven mechanism to create a healthy, happy life because local communities play an essential part in rural sustainable development (Rashidpour et al., 2010).

Therefore, researchers and research participants have undertaken this research to study together and identify what the Indicators are for creating a healthy life in communities. By identifying the Indicators, will eventually lead to determining the health problems, education, community environment in regards to all 6dimensions or measurements involved the development of characteristics associated with health outcomes is a measure community conditions and associated communications in public and communities by community members. The objectives of this research include; (1). To find the leading Health in a village communities in sub-district in propelling the recording of the community health conditions. (2). to have the leading members of the community and community members work together to create and develop the Indicators or indicators of good Health in their community and be able to communicate and provide the public with useful healthcare information. 


\section{J. Social Sci., 7 (4): 627-631, 2011}

\section{MATERIALS AND METHODS}

Research area and methodology: The research areas of conducting this study were Roi Et and Maha Sarakham provinces. The focused group in the study consisted of 6 sub-district obtained using the cluster sampling technique, of large-sized, medium-sized and small-sized sub-district with totally 79 communities. There were these 4 sub-district: Sub-district Nong Waeng, Sub-district Lao Luang, Sub-district Sing Khok and Sub-district Nan Om with 52 communities in District of Kaset Wisai, Roi Et province; and these 2 sub-district: Sub-district $\mathrm{Na}$ Kha and Sub-district Pracha Phatthana with 27 communities in District of Wapi Pathum, Maha Sarakham province.

The study was conducted from November 2008June 2009. Research participants comprised: (1) major researcher who facilitated and promoted the team of researchers to generate learning, (2) research participants who were developers performing their duties in coordinating with the focused group in the study area (3) health condition researchers, actual practitioners, core leaders of community health conditions at the sub-district level, 15 people each, with a total of 90 people; (4) representatives of focused group sub-district administrative organizations who facilitated operation in all 6 sub-district areas, 5 representatives each, with a total of 30 ones. The instruments used for collecting data were a survey of community general data, structured- and unstructured interview forms, note-taking forms on meetings and performance, a report form on activities, a handbook in supplement to organizing activities, a camera and a video camera. The methodology used was research and development by applying participatory action research in accordance with the works of McIntyre (2008), Gonsalves (2005) and Pound, (2003). The data were analyzed by synthesizing to be charts of the learning process leading to community health condition development according to the purposes and issues of the study. The statistics used for analyzing the quantitative data were percentage, mean and standard deviation. Data validities were checked using the triangulation technique. The study results were presented by means of a descriptive analysis.

\section{RESULTS}

Model of developing community health conditions for well-being: From the research and development of adapting Participatory Action Resource in Phase 1 can be concluded as a diagram which was created to develop quality community Health in communities in the province of Roi-Et and Mahasarakham ilusstrated in Fig. 1.

Identifying community lead researchers and community health indicators: To search and identify key leaders to be trained as researchers in communities at the sub-district level by initially surveying at meetings and community seminars to explain the objective of the development project to improve the health of communities so that every community member can live a happy peaceful life. Identifying and training beneficiaries as researchers will best help the community (Jackson and Kassam, 1998). 6 individuals will be selected from each of the villages and 1 individual will be chosen to represent their respective village as a participant researcher in the project. The two leadership groups will form a network of cooperation at the sub-district level. There will be the exchange of knowledge and everyone will be involved in the analysis of problems, identify the causes or Indicators and find a solution to the problem or issue. The network will together decide on the needed measures or tactics needed to tackle the problems and layout the activities needed are required. Questions will be raised before and after the Indicators are identified and how it will affect or benefit the community. The learning experience gained from working through the networks will help create personal relationships that nurture kindness and generosity and help service the community through the management of available resources within the community and to appreciate their own indigenous knowledge (Chantarasombat, 2009). The process is a mechanism that will help create local community health researchers that are qualified, have good human qualities and are capable of guiding the community in the volatile changes of modern society (Chantarasombat and Srisa-ard, 2009). At least 15 community health researchers will be created in the sub-district which will work with the network at a district level, District Public Health Department, working with the sub-district administrative organization, sub-district government officials and agencies and other government officials responsible for community development in all aspects.

To explore current healths issues and conditions and identify them as community health Indicators for a Happiness. Conference keynote speaker is clear. Tools to collect the survey data is open ended questionnaires and specific questionnaire for participants to fill and answer. The questionnaires and forms were collected from participant from the selected villages to ensure that the key range is $80 \%$ of village members participate. 


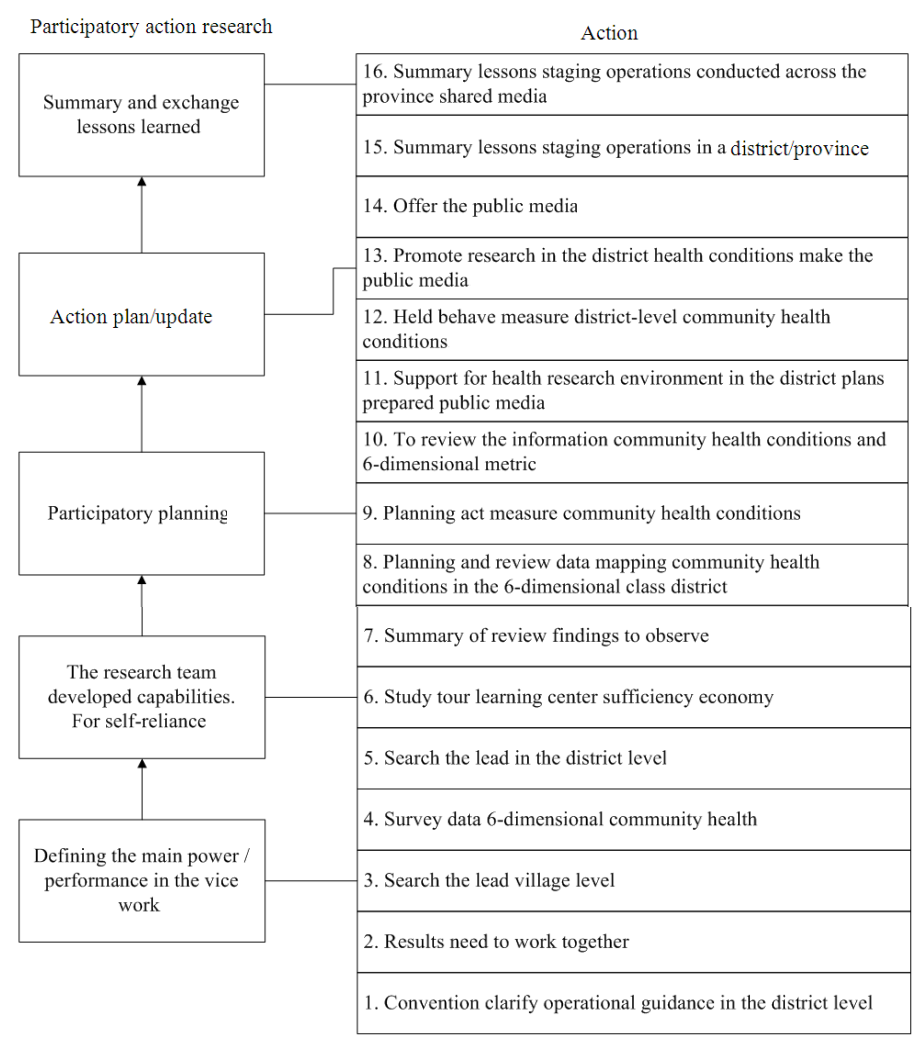

Fig. 1: Phase 1, diagram of the development of creating community health conditions for happiness in the provinces of Roi-et and Mahasarakham, Thailand

The 5 methods or mediums included (1) Radio broadcasts of the health show called "Khon Rak Sukaphap" (People who love their health), Local cultural performances of folk singing called "Moh Lum" performing stories of healthcare and information, local village communication "tower", Village sign describing the history, vision and motto of the village. (2) Every sub-district participated in the project and created a map with summaries of the health conditions and Indicators of their community. The maps were made on large sheets of vinyl or other available materials and each of the sub-district detailed their own plans and practices to produce practical public mediums for their communities.

The Indicators to indicate the success of the objectives on the community's health condition or the successful development of the project is divided into 6-7 main issues or dimensions selected by the participants of the research which are (1) Physical Health, (2) Psychological Health, (3) Social Health, (4) Intellectual Health, (5) Leadership, (6) Community Organization and Network, (8) Environment, (9) Relationships, (10) Education, (11) Sufficient economy. These issues are the important health dimensions that were applied to village communities in the 5 sub-district of the sampling group. Selected health Indicators selected by researchers were experimented in the community of Lao Luang and proved to be practical when applied to the community in Nong Waeng sub-district and the health network leaders were able to apply the Indicators with success.

\section{DISCUSSION}

Seeking key leaders of health researchers at the sub-district level began from the meeting forum for explaining the operation according to the project for development and research on community health conditions for happiness with 6 people from each village. Then 1 representative from each village was selected to be the researcher to work at the sub-district level. The community health condition researchers at both levels worked in networks. They had learning sharing, cooperatively analyzed problems, causes and guidelines for problem solving and determining needs and plans for cooperative operation at the sub-district level. Next questions to ask were: Which work should we do together first and later? What benefit will occur 


\section{J. Social Sci., 7 (4): 627-631, 2011}

to the public and to each people? And how? Learning originated from experience would link work of local people to love, unity and help with each other and management of resource capital at the sub-district level. Finally health condition researchers with potentials in major competency and minor competencies were obtained. They realized the values of humanity and could adapt themselves to the changing society. There occurred key 6 headers of community health condition researchers at the sub-district level participating in activities in continuity, 15 core leaders from each subdistrict. In addition, there occurred work mechanisms of connection at 2 more levels: (1) district of level comprising local district of and district of public health; and sub-district level comprising sub-district administrative organization presidents, policy and plan analysts, health promotion officials and community development officers who were coordinators and supporters on different stages forums.

For surveying current conditions, problems and needs for determining indicators of community health conditions for happiness, the researcher held meetings to provide explanations by resource persons. The instruments used for collecting data were open-ended and closed-ended questionnaires. Filling in data, questioning and checking data could cause resurvey to update data from the team of health condition researchers which covered 80 percent of the villages. Then they summarized the data about the villages as a whole which were different. Indicators of the community health conditions had to be reviewed before leading to plans and making projects of sub-district administrative organizations in the following phases.

For surveying 6-dimensional community health conditions at village and sub-district levels, the techniques used were holding the meeting for explaining and actual practice in 2 phases: (1) surveying maps which formal and informal leaders formed occupational groups and then the maps were presented for checking completeness, (2) surveying maps of 4-dimensional community health conditions: physical, mental, social and intellectual dimensions by making maps at the village level first and then summarized to joint maps of the villages and on the forum of learning sharing at the sub-district level in making maps of 6-dimensional community health conditions and on the forum of, learning sharing at the cross-sub-district level to have revision and making a directory of additional health condition leaders. This was the repletion to originate revision of validities of data.

Planning for production of community public health condition media at the sub-district level was in 2 phases: (1) in the pilot experimenting phase in interested sub-district with potential first of all in subdistrict with network at the district of level of 7 District of Kaset Wisai to be used as the model of public media for network sub-district to learn including Sub-district Lao Luang and Sub-district Nam Om. At the beginning of the learning phase, it was found that Sub-district Lao Luang produced 5 items of public media which achieved the established requirements. These items were: a community radio program on "People Who Love Health", Molam Singing for Health, Writing Phaya Verses to Create Health, News Tower and Monthly Brochures. Sub-district Nam Om also produced 5 items of public media including: printed matter media of monthly brochure, village news spreading tower; signs of the village history and slogan, songs introducing the village and a video on subdistrict. (2) Every sub-district participating in the project made maps as a whole of sub-district with summarized contents of 6-dimensional community health conditions. They used cloths or other different forms as needed. The brief community health conditions in different dimensions did not exceed 5 items/dimension. Each sub-district had concrete action plans for producing public media.

The developed indicators of success in operating community health conditions for happiness could be divided into these 6-7 major issues based on the issues of problems and needs for solving: physical, mental, social, social, intellectual, environmental, network and connecting relationship aspects. These aspects were used for the 5 target sub-district: Sub-district Nong Waeng, Sub-district Sing Khok, Sub-district Nam Om, Sub-district Na Kha and Sub-district Pracha Phatthana. As for the indicators of health conditions of Sub-district Lao Luang which would be tried out using the academicdeveloped indicators as neutral indicators, the indicators mentioned were tried out with Sub-district Nong Waeng. It was found that the assessors and the practitioners could concretely read and implement these indicators.

For the operation of community health conditions at the sub-district level for happiness by applying the developed 5-stage participatory action research to the operation according to $16 \mathrm{sub}$ activities, it was found that it could be actually operated appropriately with congruence and feasibility in the type of learning from action of community health condition researchers in all the 6 sub-district by using research and development for creating the community-based new body of knowledge. From an evaluation of after action note-taking, it was found that every health condition researcher increased his/her knowledge and understanding of 6-dimensional health condition data survey, making maps of 6-8 dimensional health conditions of each sub-district, ability to develop indicators of health conditions to be appropriate to their own sub-district and ability to make appropriate public health condition media by themselves. 


\section{CONCLUSION}

The developed model of community health condition development for happiness was appropriately feasible, actually practical and congruent between the participatory action research according to the required stages and the operation according to activity sub plans which were operated and improved at the same time. It generate flexibility, was an appropriate process; and the results could generate suitable mechanisms of working together with the local context and environment at a good level. These results were obtained from evaluation, summarization, feedback, note-taking after each action and forum for learning sharing of subdistrict health condition researchers. They realized that participation in operation and learning from action in the first phase was very important. It was formation of the team of sub-district-level health condition researchers by supporting from involved parties both inside and outside the sub-district. It also indicated participation in group formation from the beginning to the end of the fixed duration which could be regarded as important database to develop further work.

\section{REFERENCES}

Chantarasombat, C. and B. Srisa-ard, 2009. Development of a knowledge management model for self reliant communities. Soc. Sci., 4: 392-396.

Chantarasombat, C., 2009. Development of a management action learning process facilitating student centered learning: Education management for local development course 0501803. Soc. Sci., 4: 424-427.
Gonsalves, J.F., 2005. Participatory Research and Development for Sustainable Agriculture and Natural Resource Management: Doing participatory research and Development. IRDC, Canada, ISBN: 1552501833, pp: 224.

Jackson, E.T. and Y. Kassam, 1998. Knowledge shared: participatory evaluation in development cooperation. IRDC, Ottawa, ISBN: 1565490851, pp: 252.

Jampawai, S., S. Pothinam, M. Kanato, P. Tongkrajai and P. Homjumpa, 2011. Model development for health promotion in the elderly participating in communities. Am. J. Applied Sci., 8: 843-847. DOI: 10.3844/ajassp.2011.843.847

McIntyre, A., 2008. Participatory action research. $1^{\text {st }}$ Edn., Sage Publications, Los Angeles, ISBN: 1412953669, pp: 79.

Pound, B., 2003. Managing natural resources for sustainable livelihoods: Uniting Science and Participation. $1^{\text {st }}$ Edn., IDRC, London, ISBN: 1844070263, pp: 252.

Rashidpour, L., S.J.F. Hosseini, M. Chizari and S.M. Mirdamadi, 2010. The pattern of local community-based management for sustainable rural development in West Azarbaijan Province. Am. J. Agri. Biological Sci., 5: 8488. DOI: 10.3844/ajabssp.2010.84.88

Wasi, P., 2007. Kanchatkan khwamru krabuankan plotploi manut sa Sukkayaphap, Sariphap Laikhawamsuk. 1st Edn., Samnakphim KrīnPanyāyān, Krung Thēp, ISBN:9748290824, pp: 104. 